\title{
LEGAL ASPECTS OF CARGO INSURANCE AS MANDATORY EXPENSES FOR SAVING A SHIP IN THE EVENT OF A GENERAL AVERAGE
}

\section{Volodymyr Shemonaev ${ }^{1}$ \\ Sergey Smirnov ${ }^{2}$}

DOI: https://doi.org/10.30525/978-9934-588-15-0-88

Abstract. During the transportation the cargo on board the vessel, a number of emergencies may occur. For example:

- grounding a vessel due to save a vessel;

- fire due to improper transportation of dangerous cargoes;

- drop container tiers due to incorrect secure containers and incorrect declaration of cargo weights;

- bad weather condition that impair the stability of the vessel.

In such situations, the Captain of the vessel is obliged to take all reasonable measures to ensure the safety of the vessel, cargo and, most importantly, the crew.

For saving a vessel may need:

- dumping some cargo overboard (this may be a cargo that interferes with the stability of the vessel in bad weather, or a heavy cargo, the dumping of which will allow the vessel to bring afloat)

- make a deviation and go to the nearest shelter port ;

- use the services of professional rescuers;

- carry out urgent repairs to the ship, during which some goods may be damaged.

If formed emergencies and the vessel and/or cargo tolerate whether deliberate reasonable damages at the time of salvation from their common danger, the shipowner may call "general average". For example, if the ship ran aground and had to reverse the main engine, the engine is running at maximum speed to go broke, a loss will be an additional cost and spent fuel same additional cost and the damage caused to the engine due to work at full capacity. All parties involved

\footnotetext{
${ }^{1}$ Candidate of Law, Associate Professor, Master Mariner, National University "Odessa Maritime Academy”, Ukraine

${ }^{2}$ Candidate of Pedagogical Sciences, Associate Professor,

National University "Odessa Maritime Academy”, Ukraine

(C) Volodymyr Shemonaev, Sergey Smirnov
} 
in a such case should share the losses incurred in proportion. The emergency efficiency of insurance companies, considerable financial reserves are necessary. Thousands of sums are needed to pay for the services of lawyers, independent experts who represent the interests of the owners of the goods in court. The insurance company should to provide a guarantee for all customers. Usually in such cases, the dispatch organization accepts guarantees from several insurance companies. Insurers are particularly interested in the legal regulation of this institute. It can be said that a general average has its own value for insurers, who compensate for the damage caused by all parties to the joint maritime enterprise, both interested in the cargo and the ship, as well as the parties at risk of freight. The timely reception by the aggrieved party of the loses in many respects depends on how the payments on general average will be provided. The assumption of delay or the slightest oversight in this case will not only cause a long delay in receiving compensation and in some cases even can prevent damages.

\section{Introduction}

If an emergency is declared as a general average, it means that the owners of the cargo transported on the vessel must pay for the rescue work of the cargo and the vessel itself. If the cargo is insured, such expenses are reimbursed by the insurance company.

Therefore, the most important issue for us is to show the benefit of cargo insurance, which not only compensates for the damage or loss of cargo, but also the mandatory costs of saving the ship in the event of a general average.

The relevance of the research topic is that the article is a comprehensive analytical study of an independent maritime law institute - a general average, as well as an insurance institute and, in particular, cargo insurance.

The scientific analysis of problems associated with the general average in Ukraine has been carried out by many domestic scientists. Among them should be named V.V. Demidenko, A.N. Shemyakina, A.O. Balobanova etc., who created the fundamental basis for further study of the issues under consideration.

The purpose of the article is to determine what work and expenses the insurance company, in which the cargo is insured, the cargo owner, the charterer and the shipowner, incurs.

The main objective of the research is to find out the characteristics of perfor-mance of obligations arising out of general average and find out problems which arise in this case in civil law. 


\section{The general average is the result of a marine accident}

General average means losses incurred as a result of intentionally and reasonably incurred extraordinary expenses or donations for the sake of general safety in order to protect against the dangers of property involved in the common maritime enterprise of the vessel, freight and transported cargo ship [1, p. 7].

A general average is a consequence of any marine casualty that creates the risk of destruction of the vessel, cargo and freight: collisions of the vessel, fire on the vessel, loss of ship stability, distress of the vessel etc. In order to prevent the death of the vessel, necessary measures are taken that entail certain costs or donations. It is these losses in the form of expenses, donations and losses that are recognized as a general average [3, p. 239].

As a general average is both an institution of private international maritime law and a civil law institute existing under national law, relations arising from a general accident are governed by both international customs (York-Antwerp rules in different editions), and national legislation (the Code of Merchant Shipping of Ukraine; maritime laws of other states; the Regulations on the Association of dispatchers and the procedure for drawing up dispatches and other regulations).

The list of types of general average contained in Art. 279 MSC of Ukraine has an exemplary rather than exhaustive character. It begins with the words 'in particular', and other losses not directly named in this article, but possessing all the features of a general average and thus falling under its general definition (Article 277 of the MSC), must also be recognized as general average.

As an exception, in some cases specifically provided for by the York-Antwerp Rules, and also by Art. 280 MSC of Ukraine, to the general average equals losses, which do not have all the necessary characteristics for this purpose.

The Merchant Shipping Code of Ukraine contains the definition of the concept of general average, the list of its types, provides the procedure for the distribution of general accident, and also contains instructions on the principle of determining the right to be applied.

Yet, Art. 277 MSC defines the concept of general average, indicating that the general average recognizes the losses incurred as a result of deliberately and reasonably extraordinary donations for the purpose of salvage of the ship, freight and cargo carried on the vessel from the common danger for them, and establishes that the general average is divided between, freight and cargo in proportion to their value [2, p. 39]. 
In the same sense, but in a more precise wording, the general average in the MSC of Ukraine is defined, where it means 'losses incurred as a result of deliberately and reasonably extraordinary expenses or donations for the purpose of salvaging a ship, freight and cargo carried on the vessel from the common danger for them' (Part 1 of Art. 277).

However, it should be noted that even such a complete description of the components (elements) of the concept of general average is not exhaustive and generally accepted.

Moreover, the disadvantage of the above position is that it rather contains an interpretation of the concept of a general average rather than an analysis of its features. In this regard, it is necessary to pay attention to the fact that the signs of a general average, as a rule, are simultaneously interpreted as conditions for the emergence of the right to its distribution, which has been specifically referred to in the literature on maritime law. If we talk about the 'conditions' of the general average (some authors even use the term 'principles', which seems not very successful, since it is more accurate to speak of 'principles of distribution of the general average', which is another legal category), then their number is obviously, should be minimal, since the term 'conditions' itself indicates that only those circumstances without which the occurrence of these relationships is impossible should be indicated.

The presence of all these features suggests that there is a general average.

At the same time, it is necessary to pay attention once again to the fact that this institute was formed on the basis of a combination of casuistic and systemic-structural principles. That is, a general definition of the concept of a general average complements the approximate list of cases (types) of actions that have resulted in losses that can be attributed to the general average. The characterization of these actions in accordance with the above characteristics is as if additional (ancillary) qualification (check) of losses as a general average. In addition, the determination of the presence of a general average on the basis of a system of features (conditions) is applied in cases where a specific situation is not listed.

\section{The York-Antwerp Rules are a set of rules governing a general average institute}

Rule A of the York-Antwerp Rules 2004 provides that a general average 'takes place if and only if extraordinary donations are made intentionally 
and reasonably or extraordinary expenses are incurred for the sake of general security, in order to protect against the risk of property, participating in a common maritime enterprise'.

In this regard, it is advisable to name here the main cases of the general average. As this list has been given more compactly in the MSC of Ukraine, we will use this law and not the York-Antwerp Rules.

In accordance with Art. 279 of the MSC of Ukraine, in the case of signs of the presence of its general signs, in particular, include:

1) losses caused by the ejection of cargo or accessories of a ship, as well as losses from damage to a ship or cargo in the course of measures for general rescue, in particular as a result of penetration of water into the holds through open hatches or other openings made therefor;

2) losses caused to a ship or cargo during the extinguishing of a fire on a ship, including losses from flooding of a burning vessel for this purpose;

3) losses caused by intentional landing a ship aground and taking such a ship aground;

4) damage caused by engines, other machines or boilers of a ship which is aground caused by an attempt to heave off the vessel from the sea;

5) extraordinary expenses related to the reloading of cargo, fuel or supplies from the ship to the sea lighters, hiring of the sea lighters and back loading on the ship, incurred in the event of landing of the vessel aground;

6) losses from damage or loss of cargo, fuel or supplies caused by moving them to the ship, unloading from the ship, reloading and stowing, as well as during storage when the costs of performing these operations are recognized as a general average;

7) expenses incurred for the purpose of obtaining aid, both with and without the rescue contract, to the extent that rescue operations were carried out to prevent danger to the ship, freight and cargo;

8) losses from environmental pollution resulting from the general average;

9) loss of freight, caused by loss of cargo, in cases where the loss of cargo is compensated in the order of distribution of the general accident, thus excluding from the freight costs that would have been incurred by the carrier of the cargo for its receipt, but due to donations were not made.

As noted above, the above list is not exhaustive. It merely provides an indication of, and a description of, the situations most common in the practice of merchant navigation, relating to the production of expenses by any 
of the participants in a maritime enterprise, to prevent the hazard common to the ship, freight and cargo. In addition, the relevant norms contain a description of the nature and the content of actions related to the general average, determine the nature and list of costs that the participants of a trading company are forced to make in one or another typical situation etc.

The new version of the General Average Code is advantageous as it takes into account recent experience in the field of general average relations, as well as the interests of the parties interested in their settlement, in particular the insurers represented by the International Maritime Insurance Union (IUMI - International Union of Marine Insurance). The fact is that in the event of an emergency marine casualty recognized as a general average, the amount of losses increases by about $10-30 \%$ due to the accrual of interest, commissions and remuneration of the dispatcher. Thus, it can be said that a general average has its own cost for insurers, who compensate for the damage that occurs to all parties to the joint maritime enterprise, both interested in the cargo and the ship, as well as the parties at risk of freight. In addition, the collection of information about the ship, the cost of cargo and accident costs and other accidental losses, the subsequent recalculation of all costs and reimbursements for the general accident - all this takes time, usually several years, if the accident is large, which prevents the quick settlement of claims against the insurer.

In 2009, after the collision of Niritpride and MSC Nikita, MSC Nikita was hit. The collision occurred on the way from Klaipeda to Antwerp near the shores of the Netherlands. The vessel transported the cargo insured by the insurance company - wood, mechanical parts and PET granules.

The collision of the vessels was declared a general average, which means that the owners of the goods whose property was transported on the vessel must pay for the rescue work of the cargo and the vessel itself. If the cargo is insured, such expenses are reimbursed by the insurance company.

The insurance company provided the insurance payment, although the cargo was intact. This amount was made up of financial assistance for the rescue of the sinking ship from three cargo owners whose cargoes were on board.

In the event of the general average, a dispatching organization responsible for rescuing people, ships and cargo shall be convened. This organization establishes the preliminary amounts of guarantees to be paid by the owners of the cargo wishing to return their property. Later, the dispatcher 
organizes the sale of non-refundable cargoes, calculates the amount of damage to all parties and the cost of restoring the ship.

After the accident on board the ship, the costs are divided proportionally between the shipowner and the cargo owners carrying their cargo on it. The higher the cost of the shipment, the greater the cost of rescue work incurred by its owner. However, if the cargo cannot be rescued, the cost of the rescue work will be less.

The insurance company must provide a guarantee for all clients. Usually in such cases the dispatching organization accepts guarantees from several insurers. It is very difficult to obtain them, since very high demands are placed on firms' reliability and solvency. If companies do not receive guarantees, they have to freeze their working capital for that time. The entire administration process is very lengthy and can sometimes take several years. If the company does not receive a guarantee, its management will have to forget about millions of revenues for a long time.

In the case of a general average, emergency insurance companies, understanding of the law of the sea, as well as considerable financial reserves are required. Thousands of money are needed to pay for the services of lawyers, independent experts who represent the interests of cargo owners in court. All these works and expenses are borne by the insurance company in which the cargo is insured. If the owner of the cargo has not drawn up a contract for insurance of the transported property, then he himself will have to make a considerable amount. The advantage of cargo insurance is that it reimburses not only the losses for damage or loss of cargo, but also the mandatory costs of saving the ship in the event of a general average.

The International Maritime Committee (CMI - Committee Maritime Interna-tional) is the 'keeper' of the York-Antwerp Rules. It is CMI that develops and adopts a new version of this set of rules at its session. A new version of the York-Antwerp Rules was adopted in 2004 (YAR 2004). Although YAR 2004 gained some popularity, especially in America, and helped to reduce the cost of a general average by more than $20 \%$ on average, for several reasons, they were not included in the pro forma shipping contracts developed by the Baltic and International Maritime Council (BIMCO - Baltic and International Maritime Council). To a large extent namely due to this the ship-owners, in particular the European ones, ignore YAR 2004, preferring to use the 1994 YAR 1994 version of the YAR, although it is outdated. 
It is perhaps IUMI who has been campaigning for over 20 years to improve the York-Antwerp edition. In order to address issues related to the innovation of the York-Antwerp Rules, in 2012 the CMI Working Group decided to revise completely the provisions of the York-Antwerp Rules, resulting in a new set of rules (York-Antwerp Rules 2016 - YAR 2016). At its session in New York on May 6, 2016, CMI adopted YAR 2016. The new edition of the General Average Rulebook is advantageous as it takes into account the latest experience in the general average relationship, as well as the interests of parties interested in resolving it in particular the insurers. Satisfaction with the approval of YAR 2016 was expressed by both BIMCO and IUMI.

The most important benefits of the new edition of the York-Antwerp Rules include the following innovations:

1. The interest is accrued annually at the LIBOR rate on the first banking day of each year in the claim settlement currency plus 4\%. In the event of a claim in US dollars, YAR 2016 provides a rate of 5.18\%, compared to 7\% under YAR 1994 and 2.5\% under YAR 2004.

2 . The fees of $2 \%$ will no longer be reimbursed. This is one of the very few novelties introduced by YAR 2004, which has been preserved in YAR 2016.

3 . The measures have been introduced to accelerate the process of settlement of a general average, for example: the exclusion of low value cargoes from the contribution to the general accident, if the cost of their inclusion exceeds the cost of their contribution, as well as a transparent process of estimation by the dispatcher of the general average payments in the absence of information from the parties.

\section{Distribution of losses in a general average between a ship, cargo and freight}

When classifying an incident as a general average and the subsequent distribution of losses between the parties to the maritime enterprise, a certain procedure exists.

The purpose of a general average is to provide losses attributable to a general average between a ship, cargo and freight charge in proportion to their value. Concretizing this principle, we can say that a general average is distributed between the participants of the carriage - the owners of the vessel, cargo and freight charge in proportion to the cost of each part of the property participating in the carriage [4, p. 239]. 
An example is the case with the ship 'Yantian Express'. Fire on January 3, 2019 in the Atlantic Ocean. Hapag Lloyd, the shipowner, has declared a general average. All the participants in the transportation must make a deposit that will compensate the rescue work to save the ship and the cargo. Initially, all cargo owners had to chip in at $30 \%$ of the total value of the cargo for a general average. However, then the situation changed and the contribution increased to $60 \%$.

It means that for the distribution of a general average, it is necessary to establish the value of all property involved in the transportation. Its total value is called the contribution value or contribution capital. When calculating the contribution value, they are guided by the main provisions formulated in rule 'XVII' of the York-Antwerp Rules. Initially, the contribution value is determined by the 'actual net' value of the vessel, cargo and freight charge at the end of the voyage. Any reduction in the value of this property before the end of the flight as a result of a private average is taken into account and entails a corresponding decrease in its contribution value. Secondly, the amount of general average losses caused by the donation of such property is added to the actual value of the corresponding part of this property [5, p. 138].

The contribution value (contribution cost value) is the total value of the property (ship, cargo and freight) in proportion to which the contributions are established to cover the losses reimbursed in the manner of distribution of the general average. The following types of contribution value are distinguished:

- ship - determined basing on the cost of the ship in damaged condition;

- cargo - determined at the moment of unloading of cargo based on the value established on the basis of the commercial invoice issued to the recipient, in the absence of the invoice - on the basis of the value of the cargo at the time of its shipment, includes insurance and freight charges, unless it is on the risk of the cargo owner. From the cost of the cargo are deducted the sums of all losses from death or damage of the cargo before its unloading or during its unloading;

- the carriage charge at the carrier's risk is equal to the lost carriage charge.

Losses for a general average are apportioned between the ship, cargo and freight in proportion to their contribution value. This means that the costs and losses incurred by one party must be borne not only by this party but also by all those who are interested in saving or preserving the property. For example, if only a vessel was saved as a result of the donation of the 
cargo and the cargo was lost, then the owner of the cargo has the right to receive compensation for his loss. If only the cargo is saved and the vessel is lost, then the costs and donations should be distributed in the same order. If nothing is saved from the property, then each party will bear its own losses, since no distribution is made in this case, although donations and expenses have been made [6, p. 23].

If the general average was the fault of one of the parties, the distribution of the losses incurred will still be made on the general average. In this case, the participants in the general average have the right to recover damages from the guilty party. This is due to the fact that to establish the guilt of either side requires a lengthy and thorough investigation of the circumstances of the incident.

The burden of proving a general average lies with the party that requires the distribution of the general average. The drawing up of a dispatch is handled by a special lawyer in the general average called a dispatcher, invited by the party.

On the basis of the statement of the interested party on compensation of losses or expenses, the dispatcher proceeds to consider the case and determine the losses in the case of a general average.

The parties shall provide the dispatcher with documents describing the incidents, amounts of losses and expenses, as well as extracts from the court logs, invoices for incurred expenses, contracts, information on the cost of cargo and the vessel at the time of the end of the voyage, as well as acts of inspection of the cargo and the vessel.

After the dispatcher examines the application and all documents attached to it, he must issue a decree characterizing the losses received, that is, whether they are a general average or a private one. The dispatcher sends this decision to all interested parties. Persons who disagree with this decree may challenge it within thirty days in a court of general jurisdiction.

If the decree was not challenged by either party or the court recognized that the act of general average had taken place, the dispatcher proceeds to the direct drawing up of the dispatch.

Based on the materials provided and taking into account the circumstances of the case, the dispatcher determines the contribution value of the property. In accordance with the nature of the expenses and losses incurred, the dispatcher is obliged to decide what costs and losses will be attributed to the general average and which to the private one. The costs for a general 
average will be shared between the parties; the costs for a private average shall be borne by the party who incurred them.

The costs and losses that have been attributed to the general average are apportioned between the ship, the cargo and the freight charge in proportion to their cost. For this purpose, the contributor determines the contribution dividend, that is, the ratio between the losses on the general average and the contribution capital. Based on the amounts received, a calculation is made between the parties. The dispatch is signed by the dispatcher indicating the date, after which it is considered completed and has the force of proof.

Interested parties have the right to challenge the dispute in court for 6 months from the date of its receipt. If during the indicated period the parties do not dispute the dispatch or the court upholds it, then the dispatch is subject to execution by receipt of the notary's executive inscription. In order for the notary to execute the executive inscription (writ), he must be provided directly with the statement of dispatch and the statement of the dispatcher stating that it has not been challenged. In the case of a court decision on dispatch, the collection of this decision and the execution of the dispatch is made in accordance with the civil law.

Thus, the dispatcher is engaged in determining whether the losses incurred relate to a general average or to a private one, and their volume is also determined. In the decree, the dispatcher characterizes the losses as to whether they relate to a general or private average, then, if all parties agree with this decision, the dispatcher draws up a statement in which it distributes the losses attributable to the general average between the parties [7, p. 69].

At the end of the calculation of the adjustments and the exact determination by the dispatchers of the size of the contribution fees, each consignee must make an irrevocable obligation to pay the necessary amount, which is provided by the consignees with a signature on the emergency bond (usually together with the statement of appraised value), and by the insurer or bank with the emergency guarantee. In the absence of a guarantee, the cargo owner is obliged to pay a cash deposit (deposit) in the amount established by the dispatchers. It is required, as a rule, from small merchants who do not always know that covering a general average must be necessary included in their insurance.

The ship owner's agent must inform the P\&I Club about the situation that happened. Everyone must be warned that upon arrival of the vessel at the port 
a sea protest will be announced and that the cargo will be issued only against the general failures of the consignees (General Average Bonds) and the general emergency guarantee of cargo insurers (General Average Guarantee).

An emergency subscription is an obligation to make a payment, regardless of the size of the calculated amount, confirmed by a guarantee of a bank or insurance company. To determine the persons responsible for contributions for a general average, the dispatcher uses the documents of the carrier (usually a sea bill of lading or manifest). Transport operators issuing their own bills of lading are usually indicated in the bill of lading / manifest as the sender, so the dispatcher will send a letter asking you to provide an average receipt to the transport operator. The letter usually contains a brief description of the details of the incident and a request for the provision of data on the value of the cargo, as well as a request to sign the average subscription (receive signed counter-guarantees).

Since transport operators are not liable for contributions for a general average for a cargo: it is the duty of the cargo owners and its insurers, they may not sign the average subscription [8, p. 39].

\section{Imperfect legislation with the provision of the necessary financial support}

In the event of a general average, with the participation of the Ukrainian cargo owner, very often difficulties arise due to the imperfection of the legislation and the provision of the necessary security. Indeed, in addition to the average subscription issued, the ship owner will require a deposit, a bank guarantee or an insurance company guarantee, subject to the cargo insurance.

The main problem is that a very small number of companies go for cargo insurance. This can be illustrated by the example of an automobile boom for the transportation of used cars from America to Ukraine. Companies simply do not have money for cargo insurance. Small companies do not insure the cargo, because the cost of used cars is low, hoping that if something happens, it is better to bankrupt the company than to pay the insurance. The cost of cargo insurance during the year exceeds the cost of several containers of cargo. Instead, the funds for the equivalent of insurance are created, from which unforeseen expenses are covered. Recently in Ukraine there are practically no companies that insure their goods. Mention of insurance causes a smile on the face of the owners of the cargo. This is inherent in 
both private and public companies. The next problem is that insurance companies do not always pay insurance.

Returning to the case of the Yantian Express motor ship, it turned out that all cargo owners with the cargo on board the Yantian Express did not insure the cargo. Therefore, a deposit for a general average, which the insurance company must make, is not paid. This means that this deposit must be made by the owners of the cargo. The owners of the cargo argue in their own way. During the time the cargo was on board, it lost value and it was cheaper to bring in a new cargo. Therefore, the cargo owner does not want to make a deposit of $60 \%$ of the value of the cargo and gives the cargo to the ship owner. Thus, the cargo owner simply forgets about his cargo. Therefore, $30 \%$ of cargo owners did not make the required deposit. This means that a huge amount of cargo will fall into the hands of Hapag Lloyd. Further, 'Hapag Lloyd' will face the problem of selling a huge amount of cargo. The market will sag, cargo prices will begin to fall.

Now it's quite obvious that more and more cargo owners will not make a deposit for a general average. So sooner or later the concept of a general average may disappear. In the world where there is overproduction of goods and not enough demand, the concept of a general average can die out. It is the easiest to refuse from a cargo than to receive it for $160 \%$ of the cost, and not now, but after a long period of time. This extremely difficult global situation exists in maritime logistics today.

According to the Law of Ukraine 'On the Procedure for Settlement in Foreign Currency', the 'currency return within 90 days' rule is applied. Since this is not realistic for the cargo owner, he is obliged to obtain an individual NBU license, or pay a penalty in the amount of $0.3 \%$ of the sum. The provision of a bank guarantee will also entail not fewer difficulties, and the costs of obtaining it through the Ukrainian banks buying it from the European Bank will amount to about $5 \%$ of the sum of the guarantee obligation.

\section{Enforcement of obligations arising from a general average}

The specific character in the fact that on the one hand the obligations arising out of general average are inherently civil-law none contractual obligations. Therefore, almost any legal means provided by general provisions of the Civil Code about obligations can be applied to ensure their implementation (Book 5. Section 1. Civil Code of Ukraine). 
On the other hand, the general average is the institute of the international private law and subject to a number of special norms that provide some special ways of ensuring securing general average payments (York - Antwerp rules, item 163, 164 Merchant Shipping Code).

There of some «classical» ways of providing get a specific character, and some in practice are not applied in general. At the same time, other civil-law ways of ensuring get a different title, interpretation etc.

Considering these specifics of the given relations, further we will consider briefly the standard provisions as to ensuring of civil-law obligations, and then compare them with the specific approach to ensuring the payment of the general average, current and generally accepted in Maritime Law.

According to the widely accepted civil concept for securing of property interests of the creditor, for reception of guarantees of its appropriate performance by the debtor, the obligation in Civil Law are special measures of influence on the debtor's property, which are established by the contract or the law. These measures consist in providing the possibility of on the debtor putting of additional burdens in the case of non-performance or inadequate performance of the obligation, or involvement in the performance near to the debtor of the third parties (the underwriter), or the allocation of certain assents? The expenses of which can be achieved by compliance with the obligation [10, p. 16].

There are five such means specifically regulated by the civil legislation of Ukraine. They are the pledge, the bail, the guarantee, the penalty and the deposit (Chapter 49 of Civil Code of Ukraine). Besides, the Civil code of Ukraine provides one more, except named above, the form of ensuring of obligations - retention (Paragraph 7 of chapter 49 of Civil Code).

Recognizing that the parties of the obligations arising out of general average, above all, are interested in the actual performance by the debtor of his duties, and when they are violated infringement - protection of interests of the creditor, it is necessary to come to a conclusion that the most important means of securing here are pledge and deduction.

In this regard here it is expedient to give only a short characteristic of pledge. The essence of pledge as additional obligations is that the creditor-pawnbroker gets the right in case of default by the debtor of the obligation secured by pledge to get satisfaction at the expense of a mortgaged property. One of features of pledge as compared with other forms 
of ensuring of obligations is the association of the properties of liability and proprietary character with the accent on the fact that the pledge of the property is provided by the time of its safety of the performance obligation by the debtor. The given circumstance is considerable advantage - the cost of this property, in most cases, does not decrease, and is transformed proportionally to the rate of inflation. Besides, the pledge in particular valuable property, as a rule, both the vessel, and cargo transported on board the vessel stimulates the debtor to take all possible measures on repayment of debts without being subjected to the possibility of the pledged property.

Another important feature and advantage of pledge is its most typical feature of it as real right based on the property right, - the right passage of. It means that the ownership of the property from the creditor (pawnbroker) as if «fobs» for the property, that is where and in whose property there was no pledge subject, it will be a subject of pledge relations by the time of the termination of the basic obligation [11, p. 17].

Thus, anyway (sale, exchange, transfer or transition by right of succession) the forced property (rights) is pledge till the moment of the termination of duties of the debtor under the basic obligation.

All these advantages make pledge ay rather attractive form of ensuring of the obligations arising out of general average.

Retention of the property of the debtor as a means of securing the obligations is referred to in paragraph 7 of chapter 49 Civil Code of Ukraine. Its essence is that the creditor who has a property, which can be transferred to the debtor, in case of default by the debtor of the obligation on payment of this property or compensation to the creditor of the expenses connected with it, can keep it until the obligation is executed. If the debtor fails to perform the obligation, the creditor has the right to meet the requirements from cost of the withheld property. (In Merchant Shipping, Code of Ukraine the right to retain the goods under Art 163).

In addition, it should be noted that to secure of execution of obligations in other legal systems, such tools are widely used as the reservation of ownership, the letter of credit, insurance agreement, currency clause.

Despite of the fact that the national right does not apply them to means of ensuring of obligations, they are of great importance for securing of execution of the agreement on general average distribution. 
Therefore further it is expediently at least shortly to characterize these means in terms of their importance, as an incentive to decision (agreement) on general average distribution in the international maritime practice.

Property right reservation is now used seldom enough though in the international commercial practice, this means is well known, and in the legislation of many countries (England, France, Japan, and the Latin American countries), it is permitted and is used as security for the payment. The essence of reservation of the property right is that at goods sale on credit if the delivery and transfer of the goods (cargo) to the buyer is carried out before its payments, the agreement makes the reservation on the preservation of property right by the seller to the goods sold until the buyer makes on it last payment.

Thus, the buyer, receiving the goods (cargo), knows that it not his property; he cannot freely dispose of it until he pays its cost. The given way of securing obligations is attractive because the seller can demand the return of the goods in case of insolvency and bankruptcy of the buyer, as well as a property title on the goods, which is in illegal possession [12, p. 63].

Letter of credit is one of the forms of non-cash payments when the bank, which opens the letter of credit (bank - the emitter), undertakes on behalf of the payer (as a rule,) be buyer to pay money recipient (the seller) or another bank to make a payment when all conditions provided in the letter of credit are met.

The formula of the letter of credit is "money against documents". Its versatility is that the payment of the buyer is actually already conducted, the money from his account is going, but on the account of the seller, it has not arrived yet. To the seller the immediate reimbursement of the shipped goods or the given services is guaranteed, and he is insured from insolvency or from refusal of payment of the goods (services) by the buyer; to the buyer, in turn, it is guaranteed that the money paid to it will not disappear not known where and will be in disposal of the counterpart only after he carries out his obligations. As to their essence, the letter of credit is in fact a safe mode of payment [12, p. 91].

The currency reservation (currency warning) is applied as a means of prevention of such a situation, if the supply with the subsequent payment the increasing inflation can depreciate the purchase price established at the conclusion of the contract. In this case, a method of the price under the contract, which is widely used in the foreign trade transactions, can be applied and is called as the currency reservation or currency caution [12, p. 93]. 
In the application of this method in the condition about the price in the contract concluded in Ukraine, there are two currencies - hryvna and currency of the coordinated country (US dollar, Euro, etc.) act. The hryvna in the contract is put in dependence on other stable currency, and thus the price of final settlements (in hryvnas) is defined according to a course change of base currency (for example, US dollar, Euro, etc.) concerning hryvna.

The essence of insurance of transactions is that under the contract of insurance the insurer policy holder (the insurance company) agrees for a fee (insurance payments) upon the accuracy of events (insured event) specified in the contract to compensate to the insurer the incurred damages entirely or partially (to pay insurance compensation within conditional contract sum insured).

Taking into account these general provisions concerning the means of enforcement of civil-law obligations, we will consider now the features of use of special means of the securing applied in relations, connected with general average distribution between the participants of the maritime enterprise.

In the publications on maritime law «provisions of general average» is defined as «money, securities and other property which is a guarantee of obligations of performance» as in the case of obligation default to compensate a corresponding part of losses they become the property of the creditor.

The way to ensure the proof is considered to be provided by the norms of the civil law the measure of prompting of the debtor to execution of a duty lying on him by joining on the force of the law or contracts to the basic obligation the additional one. The basic obligation is reimbursement of the loses, one is provision of appropriate security.

The ways to ensure can be established by instructions of statutory acts or be based on the contracts. Each of the method has the specificity and therefore they have different impaction the debtor and protect the interests of the creditor.

To ensure the obligation in the general average is the responsibility of the Captain of the vessel.

In particular, Art 163 Merchant Shipping Code of Ukraine sets that «...The receiver is obliged in case of general average to bring an emergency payment or to give appropriate securing». In this case, the requirement to provide by the consignee of payment securing of the share of the general average, which is due to it, is a duty of the Captain of the vessel. He has no right to give out cargo before securing reception. The implementation by the 
Captain of the vessel of the mortgaging right to the cargo is in this case the means of compulsion of the consignee to give securing in this or that form.

In the field of merchant shipping as the form of securing of performance of obligations an emergency subscription, an emergency payment, the deposit, a bank guarantee, a guarantee of an insurance society, a guarantee of Club of a mutual insurance are applied.

The emergency subscription is a written obligation of the consignee to pay a share of general average, which will be due according to the consignee of the average adjustment, and provide to average adjuster required for drawing up average adjustment documents, materials, data, to declare the cost of the cargo.

The deposit is applied in cases when it is impossible to collect from the consignee a cash security in the preparation of the general average subscription [12, p. 218]. In order to avoid abuse from shipowners those sums which can be received in the form of deposits from the cargo owners, York-Antwerp (a rule XXII) rules provide that similar preliminary deposits should be brought into the special account opened in the name of the two co-trustees - one will be appointed by the shipowner, and another by the person, introducing deposits, or the insurer of cargoes. The sum deposited this way together with the percent should serve as securing of payment for those parties who have the right on general average. The trustees have the right to make payments or return on deposits in the written certifications of average adjuster who settles an invoice on general average [11, p. 29].

The guarantee is applied very often. Instead of reception, the money or the deposit the shipowner in securing of payments on general average accepts a bank guarantee. In this case, the shipowner specifies the guarantee of which bank to accept $[9$, p. 3].

\section{Conclusions}

Modern theory and practice of the law of the sea under the general average means losses incurred as a result of intentionally and reasonably extraordinary expenses or donations made for the common security in order to protect against the danger of property involved in the common maritime enterprise of a ship, freight and transported ship.

In the case of a general average, emergency insurance companies, understanding of the law of the sea, as well as considerable financial reserves are required. Thousands of money are needed to pay for the services of law- 
yers, independent experts who represent the interests of cargo owners in court. All these works and expenses are borne by the insurance company in which the cargo is insured. If the owner of the cargo has not drawn up a contract for insurance of the transported property, then he himself will have to make a considerable amount. The advantage of cargo insurance is that it reimburses not only the damage for damage or loss of cargo, but also the mandatory costs of saving the ship in the event of a general accident.

Thus, it can be concluded that a general average has its own cost for the insurers, who compensate for the damage that occurs to all parties to the joint maritime enterprise, both interested in the cargo and the ship, as well as the parties at risk of freight.

The variety of types of general average losses, the presence on the ship of cargo of a large number of different owners make the distribution of a general average quite laborious, requiring special knowledge and experience. Complications arising from a general average cannot be resolved without the help of professional dispatchers and lawyers.

Since transport operators are not liable for contributions for a general average for a cargo: it is the duty of the cargo owners and its insurers, they may not sign an average receipt.

In the event of a general average, with the participation of the Ukrainian cargo owner, quite frequently the difficulties arise due to the imperfection of the legislation and the provision of the necessary safety. Indeed, in addition to the average subscription issued, the shipowner will require a deposit, a bank guarantee or an insurance company guarantee, subject to cargo insurance. Therefore, the mechanism of financial support for a general average for Ukrainian cargo owners requires debugging.

The main problem is that a very limited number of companies go for cargo insurance. They simply do not have money for cargo insurance. Small shipowners do not insure the cargo, because the cost of the cargo is small, hoping that if something happens, it is better to bankrupt the company than to pay the insurance. Cargo owners do not insure cargo for the same reason. The cost of cargo insurance during the year exceeds the cost of several containers of cargo. Recently in Ukraine there are practically no companies that insure their goods. This is inherent in both private and public companies.

The next problem is that insurance companies do not always pay the insurance. 
The biggest fundamental problem is that a general average is now a very difficult phenomenon for a shipowner. Now it's quite obvious that more and more cargo owners will not make a deposit for a general average. So sooner or later the concept of a general average may disappear. In the world where there is overproduction of goods and not enough demand, the concept of a general average can soon die out.

\section{References:}

1. Zhilin I. S. General accident and maritime law issues (1951). M.: Mor. Transport, 80 p. (in Russian)

2. Code of Merchant Shipping of Ukraine (1995). Information of the Verkhovna Rada of Ukraine (BB), Nos. 47, 48, 49, 50, 51, 52, Article 349. (in Russian)

3. Sidorenko A. V. (2001). Extraordinary marine incidents (legal aspects) Odessa: Latstar, 400 p. (in Russian)

4. Code of Merchant Shipping of Ukraine (1995). Information of the Verkhovna Rada of Ukraine (BB), Nos. 47, 48, 49, 50, 51, 52, Article 349. (in Ukrainian)

5. Sidorenko A. V. (2001). Emergency marine accidents (legal aspects). Odessa: Latstar, 400 p. (in Russian)

6. Grevtsova T. P. (2008). Responsibility of the sea carrier for cargo non-safety. L. 40 p. (in Russian)

7. Yulberdina L. R., Khamidullina G. V. (2017). Provisional measures in the civil process. Collection of articles of the VIII international scientific and practical conference, part 2, Moscow, April 30 / Ed. V.B. Solovyov. Moscow: 'Scientific and Publishing Center' Actuality. RF. (in Russian)

8. Yarmolovich R. P., Udolaty A. A. (2010). General average, its importance in commercial exploitation of the vessel. Proceedings of the Scientific and Methodological Conference 'Modern Problems of Improving the Safety of Navigation' October 7-8, 2009. Odessa: ONMA. P. 124-125. (in Ukrainian)

9. Aliev S. B. (1999). Ways to enforce obligations. Legal newspaper. Almaty. No. 21. P. 3.

10. Borodenko S. (2001). Collateral as a form of securing bank loans. Economics, finance, law. No. 4. P. 16.

11. Vinogradov P. P. (1937). Insurance of ships and registration of an accident at sea. K.: Gun. - M.: Gosfinizdat, 127 p.

12. Civil law: definitions, concepts, legislation / ed. E. O. Kharitonova. Kharkov: Odyssey, 1998. $383 \mathrm{p}$. 